\title{
IDENTIFICAÇÃO E QUANTIFICAÇÃO DAS FRAGILIDADES TECTÔNICAS ASSOCIADAS ÀS FALÉSIAS ENTRE TRANCOSO E CARAÍVA, COSTA DO DESCOBRIMENTO-BA
}

\author{
$\underline{L i ́ v i a ~ F e r r e i r a ~ A l v e s ~}^{1}$ e Carlos César Uchôa de Lima ${ }^{2}$ \\ 1. Bolsista PROBIC/UEFS, Graduanda em Engenharia Civil, Universidade Estadual de Feira de Santana, e-mail: \\ liviaaa.fa@gmail.com \\ 2. Orientador, Departamento de Ciências Exatas, Universidade Estadual de Feira de Santana, e-mail: \\ uchoamaster@gmail.com
}

PALAVRAS-CHAVE: falésias; fragilidades tectônicas; recuo das encostas.

\section{INTRODUÇÃO}

Em território brasileiro, atividades tectônicas que ocorreram a partir do Mioceno Médio, são consideradas como um dos principais elementos na configuração de muitas paisagens, em particular, na região costeira do Brasil (Hasui, 1990). As pesquisas com essa temática em áreas costeiras têm como principais referências as estruturas presentes nos sedimentos da Formação Barreiras que, segundo Lima (2000), é um complexo sedimentar que apresenta um relevante significado tectônico.

No litoral sul da Bahia, a Formação Barreiras aflora em falésias, entre Trancoso e Caraíva. A grande maioria das feições geológicas vistas atualmente foi resultado de processos tectônicos que ocorreram do Neógeno ao Pleistoceno. As falésias encontradas são muitas vezes ativas e estão inseridas em ambientes de grande uso e ocupação do solo. Esta pressão antrópica intensa junto aos processos naturais, acaba provocando modificações físicas na região, tornando-a uma zona com alto nível de instabilidade e consequentemente, de favorecimento dos movimentos de massa.

Este trabalho tem como objetivo, fazer uma análise estatística das juntas tectônicas presentes na Costa do Descobrimento, mais especificamente entre as localidades de Arraial D’Ajuda e Trancoso, pertencentes ao município de Porto Seguro, sul da Bahia. Ao se determinar os planos de fraqueza é possível avaliar o risco de fluxos gravitacionais e assim sugerir medidas preventivas a fim de evitar os transtornos advindos desses movimentos.

\section{MATERIAL E MÉTODOS OU METODOLOGIA (ou equivalente)}

No presente trabalho, além do levantamento bibliográfico de artigos com a mesma temática, estudos de campo foram desenvolvidos a fim de observar e interpretar as estruturas geológicas que indicassem a ação do neotectonismo nas falésias da Formação de Barreiras. Foram realizadas medidas dos planos de fraqueza e ângulo de corte das encostas utilizando a bússola geológica e obtenção de coordenadas UTM por meio do GPS, ao longo da área estudada. Com base nos dados obtidos, foi efetuado um tratamento estatístico com o auxílio do software StereoNET. Com o intuito de expor os planos de fraqueza e os níveis de recuo das encostas, foram feitas fotografias digitais.

\section{RESULTADOS E/OU DISCUSSÃO (ou Análise e discussão dos resultados)}

Muitas pesquisas na região da Costa do Descobrimento, entre Trancoso e Caraíva (Figura 1), destacam que a neotectônica vem sendo alvo de diversos estudos, devido a 
sua relação com os planos de fraqueza e consequentemente, com a evolução da crosta continental. Cruden e Varnes (1996) apud Ahrendt (2005) apresentam grupos de fatores que também influenciam na ocorrência de movimentos gravitacionais de massa. São eles: agentes geológicos; morfológicos; físicos e antrópicos. Quando os agentes geológicos são citados, torna-se imprescindível a abordagem da influência exercida pelos planos de fraqueza, sobre o desencadeamento dos movimentos de massa e o recuo das encostas.

Figura 1. Mapa de localização da área de estudo no sul do Estado da Bahia.

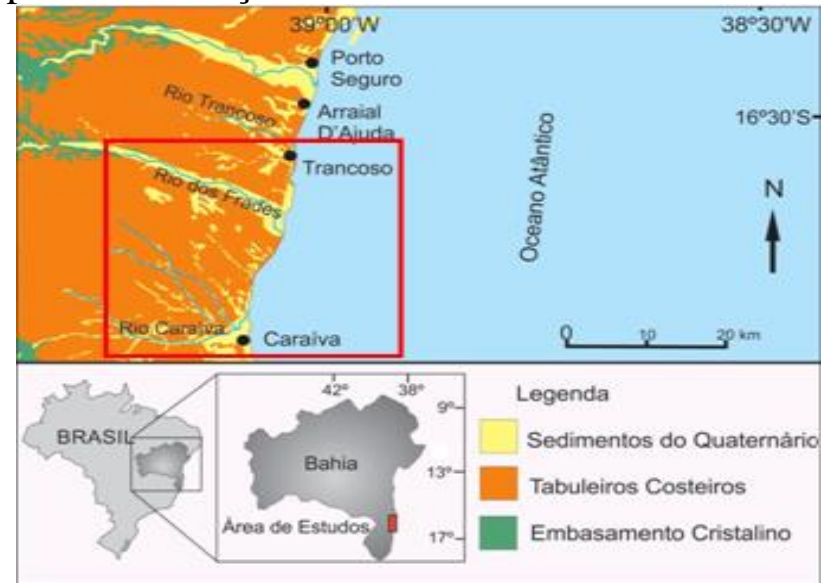

(Fonte: Modificado de Lima e Nolasco, 2015)

Segundo vários autores (COELHO E LIMA 2006, DANTAS E LIMA 2008, LIMA ET AL 2008 e LIMA 2010), a maior parte dos movimentos de massa que ocorrem em áreas costeiras são condicionados por estruturas geológicas, representadas principalmente por juntas tectônicas. Tais movimentos ocorrem, via de regra, associados à percolação de água nas descontinuidades, aumentando o grau de erosão e provocando o surgimento de pressões hidrostáticas. Como ponto crítico desse mecanismo, vários deslizamentos podem ocorrer, os planos de fraqueza determinados por essas juntas coincidem, na maioria das vezes, com a direção preferencial desses deslizamentos.

Barton (1971) apud Guidicini e Nieble (1984) cita que haverá casos em que o aparecimento de fraturas será o primeiro passo para um rápido processo de colapso, sendo que em suma, fendas de tração devem ser consideradas como indícios de instabilidade, permitindo assim planejar e quantificar o volume de trabalhos de investigação que se julgar conveniente em cada caso.

As zonas de fraqueza identificadas na região estudada revelaram a ação do neotectonismo, além disso, apresentam grande quantidade de estruturas geológicas, tais como, juntas e falhas que são capazes de facilitar os fluxos gravitacionais, provocando o recuo das encostas (Figura 2).

Figura 2. (a) Juntas tectônicas observadas no litoral sul da Bahia; (b) Falha geológica com abatimento do bloco a direita do observador; (c) juntas paralelas às falésias, facilitando a percolação de água e movimentos de massa; (d) estrias no plano de falha. 

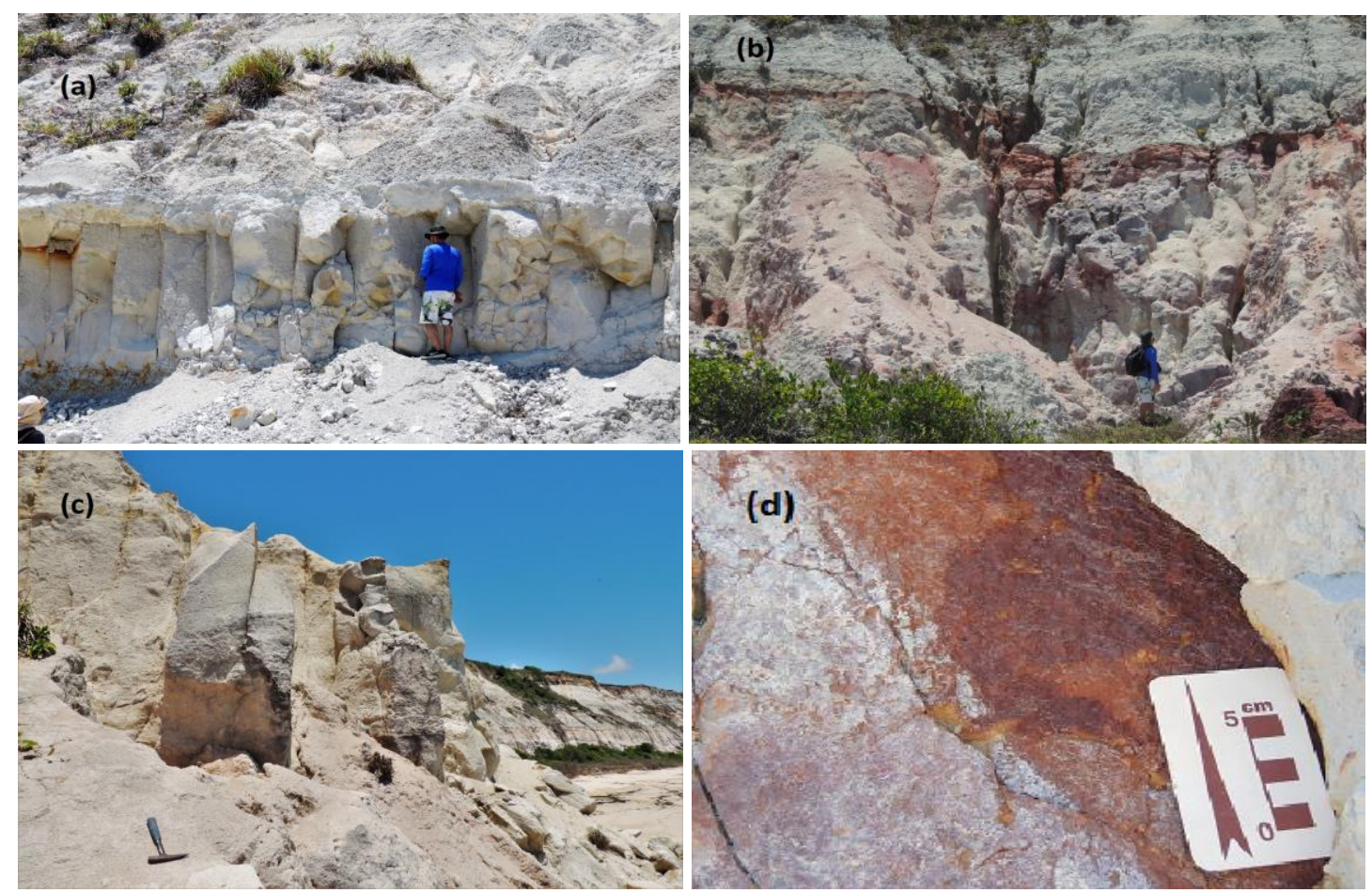

Durante as pesquisas em campo, foram tomadas várias medidas das juntas neotectônicas ao longo da área de afloramentos estudados. Para as 481 medidas efetuadas, as análises desenvolvidas revelam que, as juntas tectônicas possuem direção predominante NW-SE, e secundariamente, planos com direção NE-SW (Figura 3).

Figura 3. Diagrama de rosetas, a partir de 481 medidas, mostrando o direcionamento médio das juntas tectônicas nos afloramentos estudados.

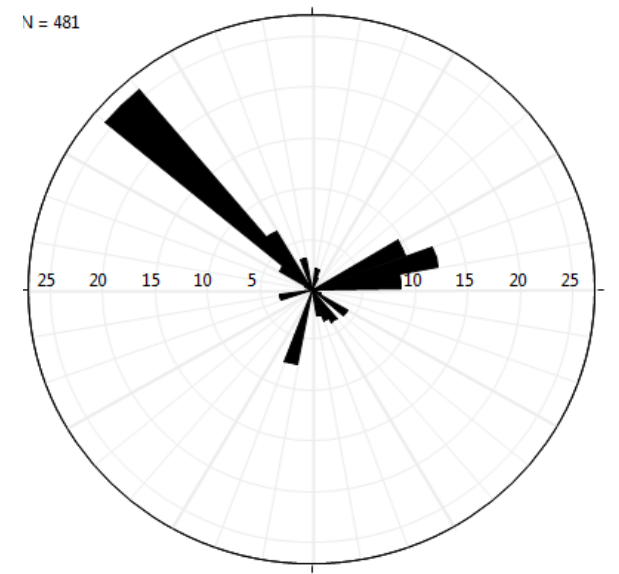

Fonte: Autor, 2018

Vários pesquisadores (Lima et al., 2006) afirmam que nesta parte do litoral brasileiro, os dados de alguns afloramentos considerados representativos, entre Prado e Porto Seguro, mostram dois sistemas de juntas orientados nas direções NE-SW e NW-SE. As duas tendências ocorrem em toda a área, embora o segundo seja mais freqüente entre Caraíva e Porto Seguro. Além disso, Lima et al. (2006) fez um estudo de medidas das juntas neotectônicas entre Porto Seguro e Prado, litoral sul da Bahia, e concluiu que, pelo menos para aquela região, as forças tectônicas que imprimiram tais juntas, também 
possuem um direcionamento NW-SE. Estabelecendo um comparativo com esses estudos feitos na mesma região, pode-se afirmar que há concordância entre os resultados obtidos e a afirmação daqueles pesquisadores.

\section{CONSIDERAÇÕES FINAIS (ou Conclusão)}

Uma análise preliminar desenvolvida na área estudada identificou uma quantidade significativa de estruturas geológicas que evidenciam a ação da neotectônica, sobre os sedimentos do Grupo Barreiras, as principais feições observadas são as juntas neotectônicas que foram encontradas em vários afloramentos. Para a Formação Barreiras, a presença de um sistema conjugado de juntas evidencia que, posterior à deposição daquele complexo sedimentar, houve a atuação de esforços tectônicos, cujo direcionamento do esforço principal máximo é a direção predominante.

Os resultados mostrados no presente trabalho evidenciam que, as juntas possuem direcionamento predominante NW-SE e que os dados estão em concordância quase que geral, de estudos interpretados pela maioria dos pesquisadores, apesar de haver planos com direcionamento NE-SW. Observou-se também, que essas juntas se constituem em fragilidades, que facilitam os processos erosivos, resultando em movimentos de massa e consequentemente, no recuo da zona costeira. Esses movimentos são facilitados pelos planos de fraquezas determinados pelas juntas tectônicas. Os planos dessas juntas coincidem, na maioria das vezes, com a direção preferencial do deslizamento. Esses estudos são importantes em regiões costeiras, pois fornecem subsídios para o gerenciamento costeiro e implantação de obras de engenharia.

\section{REFERÊNCIAS}

AHRENDT, A. Movimentos de Massa Gravitacionais - proposta de um sistema de previsão: aplicação na área urbana de Campos do Jordão - SP. Tese (Doutorado) Escola de Engenharia de São Carlos, Universidade de São Paulo. São Carlos, 2005.

GUIDICINI, G.; NIEBLE, C.M. Estabilidade de Taludes Naturais e de Escavação. Edgar Blücher. São Paulo, $2^{a}$ ed, 1984.

HASUI, Y. 1990. Neotectônica e aspectos fundamentais da tectônica ressurgente no Brasil. In: SBG/MG. Workshop sobre neotectônica e sedimentação cenozóica continental no sudeste brasileiro, Belo Horizonte. Boletim 1:1-31.

LIMA, C.C.U. 2000. O Neotectonismo na costa do Sudeste e do Nordeste brasileiro. Revista de Ciência \& Tecnologia.UNIMEP, 15: 91-101.

LIMA, C.C.U. Evidências da Ação Tectônica nos Sedimentos da Formação Barreiras Presentes no Litoral de Sergipe e ao norte da Bahia. Revista de Geografia. Recife: UFPE - DCG/NAPA, v. especial VIII SINAGEO, n. 1, Set. 2010.

LIMA, C.C.U.; DANTAS, J.J.R.;COELHO,M.G.A. Fragilidades tectônicas nas encostas das rodovias litorâneas de Sergipe e Extremo Norte da Bahia. Universidade Estadual de Feira de Santana, UEFS - Feira de Santana, 2008.

LIMA, C.C.U.; VILAS BOAS, G.S.; BEZERRA, F.H.R. 2006b. Faciologia e análise tectônica preliminar da Formação Barreiras no litoral sul do Estado da Bahia, Brasil. Geologia-USP Ser.Cient. São Paulo, (6)2: 71-80. 